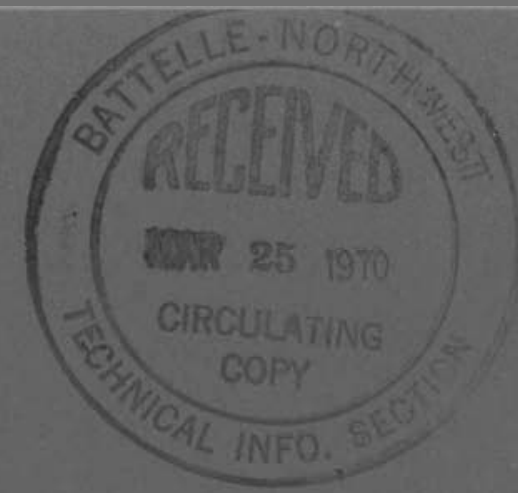

BNWL-1287

UC-23

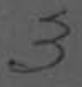

$2-70$

\title{
FAIL SAFE INSTALLATION OF A VACUUM SYSTEM FOR SPUTTERING APPLICATIONS IN A GLOVE BOX
}

W. J. Coleman

February 1970

\section{AEC RESEARCH \& DEVELOPMENT REPORT}

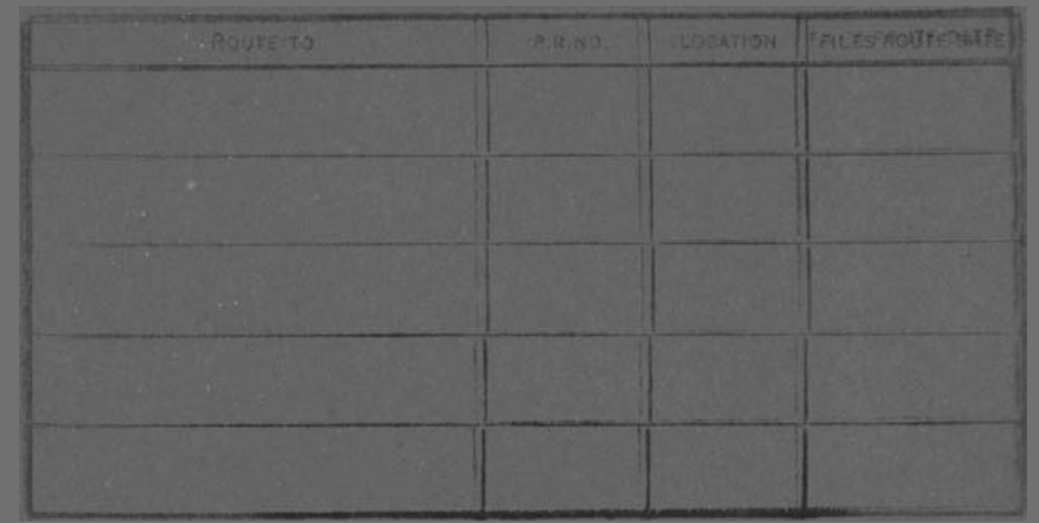




\section{LEGAL NOTICE}

This report was prepared as an account of Government sponsored work. Neither the United States, nor the Commission, nor any person acting on behalf of the Commission:

A. Makes any warranty or representation, expressed or implied, with respect to the accuracy, completeness, or usefulness of the informotion contoined in this report, or that the use of any information, apparatus, method, or process disclosed in this report may not infringe privately owned rights; or

B. Assumes any liabilities with respect to the use of, or for domages resulting from the use of any information, apparatus, method, or process disclosed in this report.

As used in the above, "person acting on behalf of the Commission" includes any employee or contractor of the Commission, or employee of such contractor, to the extent that such employee or contractor of the Commission, or employee of such controctor prepares, disseminates, or provides access to, any information pursuant to his employment or contract with the Commission, or his employment with such contractor

PACIFIC NORTHWEST LABORATORY

RICHLAND, WASHINGTON

operated by

BATTELLE MEMORIAL. INSTITUTE

for the

UNITED STATES ATOMIC ENERGY COMMISSION UNDER CONTRACT AT(45-1)-1830 


\author{
BNWL - 1287
}

UC-23, Radioisotope and Radiation Applications

\title{
FAIL SAFE INSTALLATION OF A VACUUM SYSTEM \\ FOR SPUTTERING APPLICATIONS IN A GLOVE BOX
}

By

พ. J. Coleman

Applied Physics Department Systems and Electronics Division

February 1970

1072370

BATTELLE MEMORIAL INSTITUTE

PACIFIC NORTHWEST LABORATORIES

RICHLAND, WASHINGTON 99352 
BNWL -1287

Printed in the United States of America Available from

Clearinghouse for Federal Scientific and Technical Information National Bureau of Standards, U.S. Department of Commerce Springfield, Virginia 22151

Price: Printed Copy $\$ 3.00 ;$ Microfiche $\$ 0.65$ 


\section{FAIL SAFE INSTALLATION OF A VACUUM SYSTEM FOR SPUTTER ING APPL I CAT IONS IN A GLOVE BOX}

W. J. Coleman

\section{ABSTRACT}

In the development of a method to contain polonium as an isotopic heat source the hollow microsphere concept was originated. In order to make this concept work many new fabrication processes were required. One of these processes involved sputtering and vacuum evaporation techniques. Due to the biological hazard, it was mandatory that the equipment be operated in a fail safe condition.

This paper deals with the procedures involved in installing a vacuum system into a radiation glove box and the modifications necessary to install a sputtering unit in this box. A major consideration in the installation of the vacuum system and sputtering unit in the radiation glove box was to provide a mechanism so that any malfunction would result in immediate shut down. That is to say, that if the power or any one of the components failed, the unit would shut down in such a way that no release of radioactive material would occur. The box in normal operation is maintained at a -1 in. of water. All mechanisms fail in such a manner as to maintain this negative pressure in the box.

The interlock system has been in operation for over 6 months. During this period, it has shut the system down several times due to abnormal glove box pressure and inadequate water flow with no adverse effects. 
BNWL - 1287

TABLE OF CONTENTS

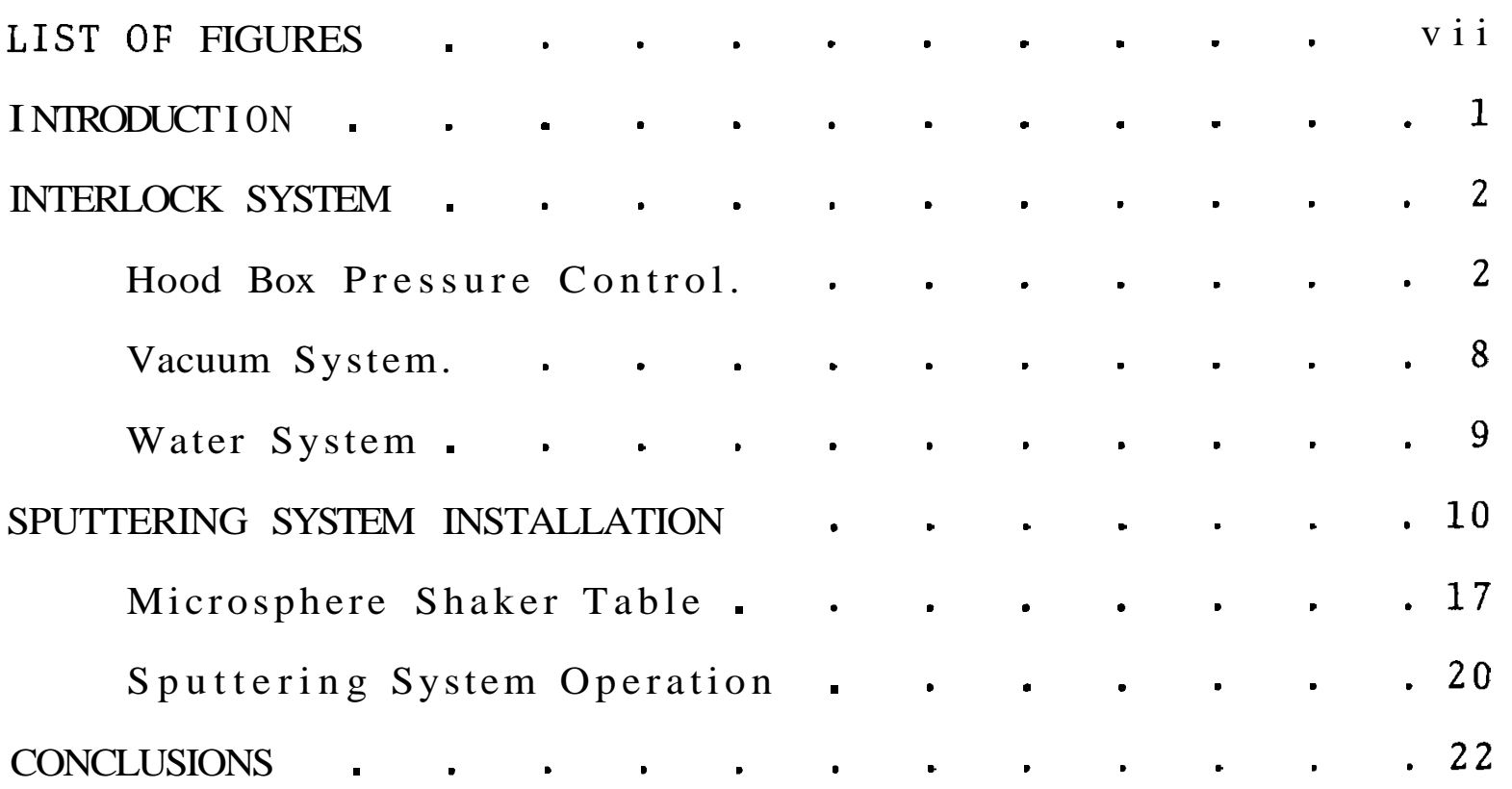




\section{LIST OF FIGURES}

1. Operational Diagram of Glove Box Interlock System 3

2. Wiring Diagram for Installing Interlock System 4

3. Schematic of Unmodified Sputron II 11

4. Schematic of Modified Sputron II 12

5. Electromagnet and Anode:-Cathode Assembly Inside Vacuum Chamber

6. Substrate Holder as Viewed Through Vacuum Chamber Viewing Window

7. Anode-Cathode Water Cooling as Viewed on Top of Vacuum Chamber

8. Microsphere Shaker Unit Inside Vacuum Chamber 18

9. Wiring Diagram of Shaker Unit Power Supply 19

10. Metallography of Fueled Microsphere with Sputtered Protective Film Overlay 


\section{FAIL SAFE INSTALLATION OF A VACUUM SYSTEM FOR SPUTTERING APPLICATIONS IN A GLOVE BOX}

\section{W. J. Coleman}

\section{INTRODUCTION}

In the development of a method to contain polonium for isotopic heat source applications, the hollow microsphere concept was originated. To develop this concept into a working model required developing many new fabrication processes. The process described here is the one occurring immediately after the microsphere has been fueled with polonium and before the strength cladding surrounding the microsphere has been deposited. Prior to this process, the microsphere was coated with a rare earth by the vacuum vapor deposition process and fueled in a reaction chamber with polonium to form a rare earth polonide. The fueled microsphere then was ready to receive the chemical vapor deposition strength cladding. The high temperatures and reducing atmosphere of this process appeared to deteriorate the fuel form. To counteract this effect, a thin film was sputtered onto the microsphere. This thin coating was not intended as a strength cladding in any sense of the word, but mainly to encapsulate the fuel form and protect it against the reducing atmosphere of the CVD process. The material used to provide the protective coating need be compatible only with the process and does not necessarily have to be of the same material as the strength cladding.

This paper deals with the procedures involved in installing a vacuum system into a radiation glove box and the modifications necessary to install a sputtering unit in this box. A major consideration in the installation of the vacuum system and sputtering unit in the radiation glove box was a mechanism assuring that any malfunction would result in a "fail safe" condition. The unit, for example, would assume 
a "fail safe" condition in event of a power failure or, would shut down in a safe condition by an interlock without releasing radioactive material should any one of the components fail. The box in normal operation is maintained at a pressure equivalent to a minus 1 in. of water. A 11 mechanisms fail in such a manner as to maintain this negative pressure in the box.

\section{INTERLOCK SYSTEM}

The hood line acts as a biological shield and containment vessel for the polonium bearing fuel. Every precaution is taken to assure $100 \%$ containment of the polonium because of its toxic and radiation hazard. To assure that the vacuum equipment meet these criteria, an interlock system was designed to protect against all conceivable events and to assure containment of the polonium and maintain the hood box at a negative pressure. Three basic systems essential to this design and described herein are:

- The hood line pressure system

- The vacuum system

- The water cooling system.

Each system, although unique in itself, is also interdependent in that safe operation will affect the operation of the other system. Figure $\mathbf{1}$ is an operation diagram of the interlock system and Figure 2 is the electrical wiring diagram for installation of the interlock system.

HOOD BOX PRESSURE CONTROL

The hood box is to be maintained at a -1 in. of water. Any deviation from this pressure in either a positive or negative way is considered hazardous. To prevent the internal system involved in the vacuum coating process from causing a pressure excursion, an interlock system was designed and installed. The pressure excursions considered here are described in sections dealing with excess pressure and excess negative pressure. 
BNWL- 1287

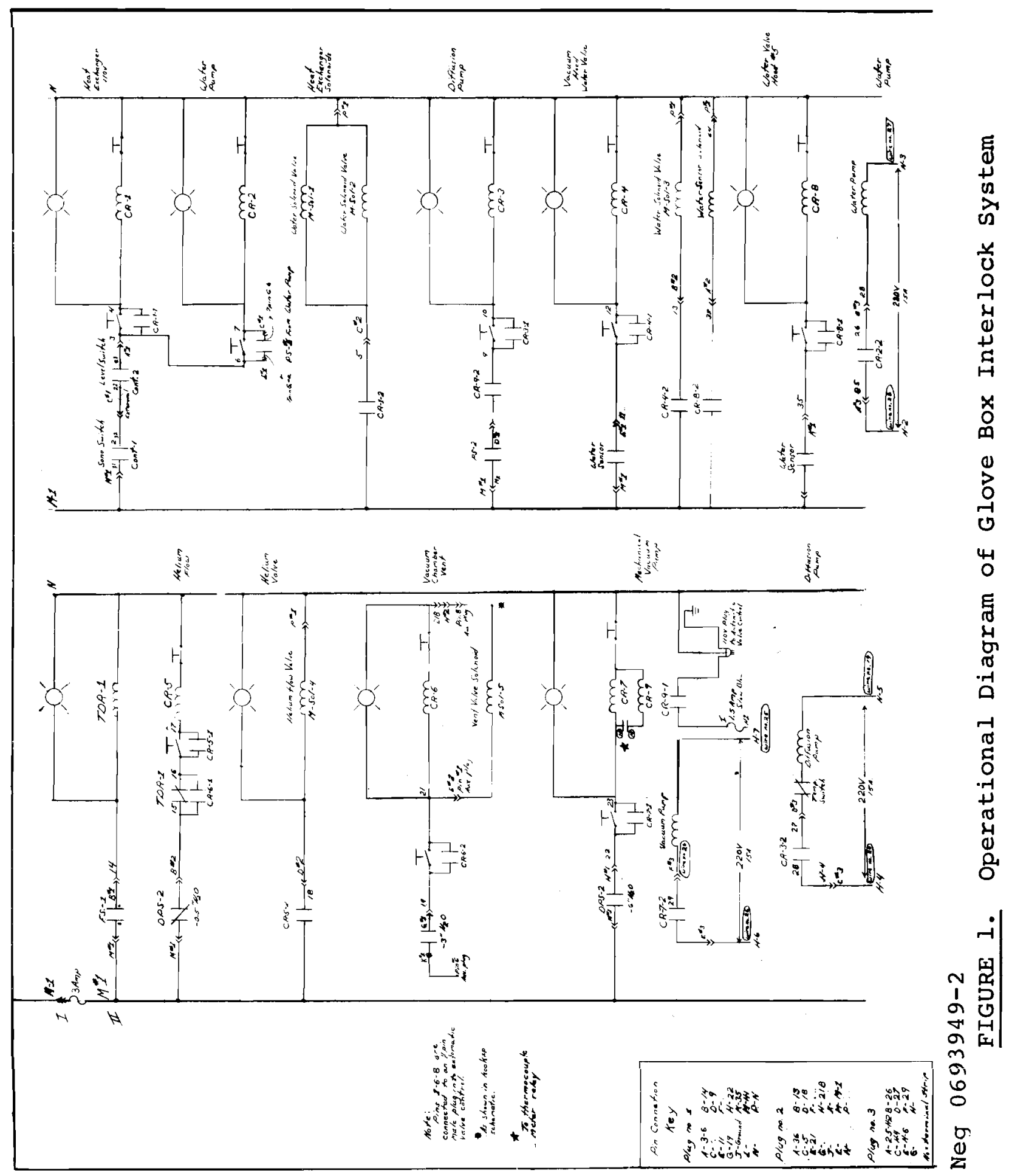


BNWL -1287

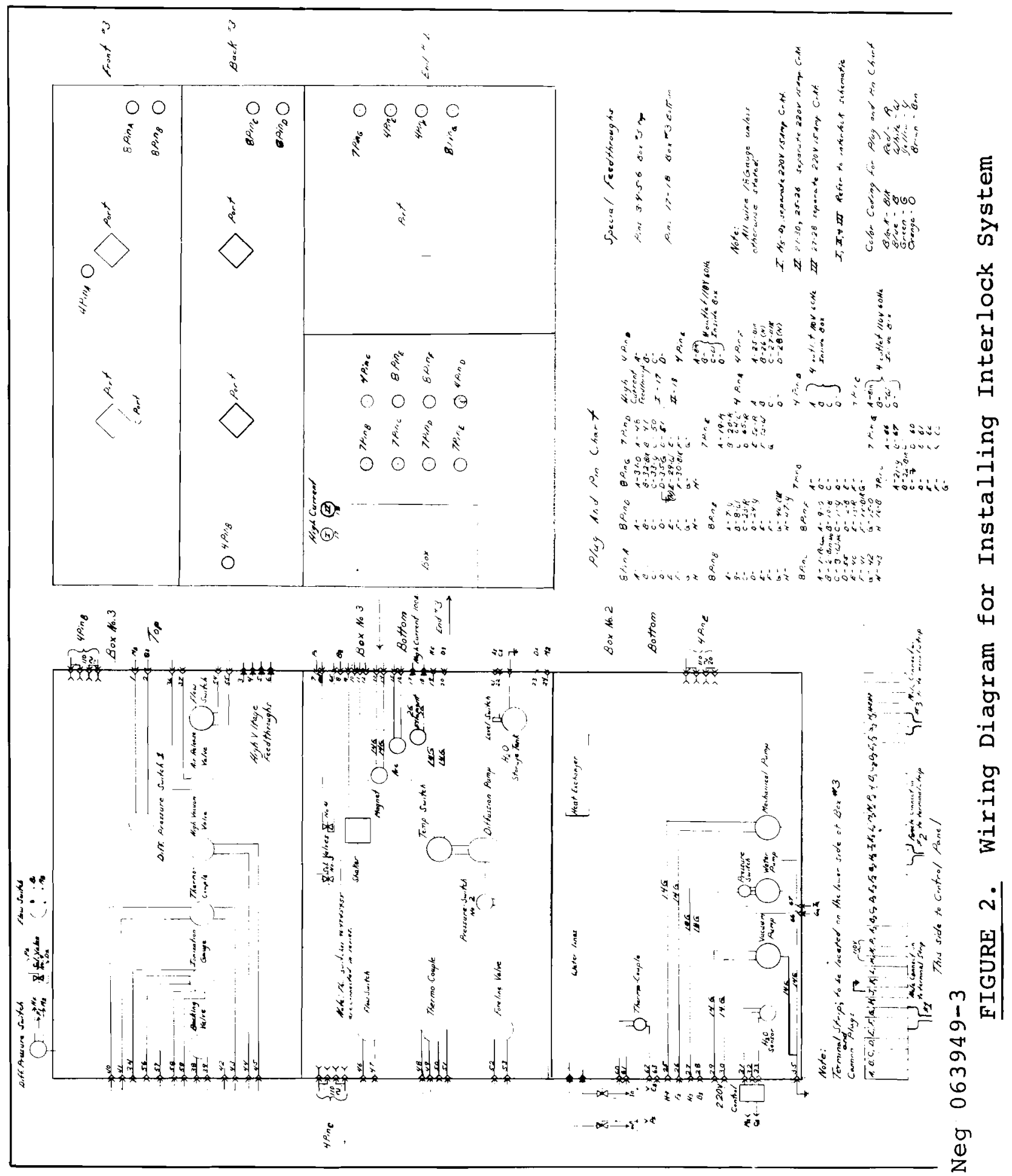




\section{$\underline{\text { Hood Line Exhaust System }}$}

The exhausts from all the boxes on the hood line are connected up to the building exhaust system, which is termed the E4 line. This line is maintained at a -4 in. of water and the boxes are controlled from this line by means of a Fisher governor valve which can be set to control from 0 to -2 in. of water. Normal setting is a -1 in. of water. To assure that no radioactive wastes get into the exhaust system proper, the lines are filtered in several locations. The main filter is located at the exhaust entrance from the hood box. To maintain this filter in satisfactory operating condition (assure that it will filter out the radioactive material), it is periodically serviced and replaced. To prevent oxidation and neutron problems, the polonium isotope hood line is continuously flushed with argon gas. The flow is manually set for a

normal rate of $50 \mathrm{f} \mathrm{t}^{3} / \mathrm{hr}$. A Fisher governor control valve used in the argon line as a safety override automatically shuts off if the glove box pressure exceeds a set point. Normally, this valve is set at -0.5 in. of water.

\section{Excess Pressure}

The necessity for maintaining the hood box at a negative pressure takes priority over any other system requirement. This pressure is maintained by the building exhaust system E4 line and controlled by the Fisher govenor valve at a -1 in. of water. The factors that can effect the hood pressure are loss of a glove, plugged E4 filter, breakage inside the glove box of a high pressure helium line exceeding the capacity of the E4 line intake, and opening the vacuum chamber if it is in an overpressure condition. With the loss of a glove, either accidentally or on purpose, the pressure of the hood box would rise nearly to atmospheric, and then remain slightly negative as the E4, in trying to maintain a -1 in. of water, draws a large influx 
of a ir into the hood. Should this condition arise, it would be essential to stop all other operations. It is rather obvious that the loss of a glove, normally a personnel accident, cannot be interlocked in any manner. Thus, good operating practices are to be observed and carefully followed to prevent such occurrences in this area. Good operating practices also apply to routine exchange of the E4 filter to prevent blockage.

Electropneumatic valves operating off of a high pressure helium line control the vacuum system. It is conceivable that this line could break and that the E4 filter, if partially blocked, could lack the capacity to maintain the glove box at the proper pressure. The vacuum chamber, consisting of approximately $4 \mathrm{ft}^{3}$, is bled up by this pressurized helium line. This chamber conceivably could be overpressurized during bleed-up and, if opened during this time, might cause a minor explosion which could pop a glove off and thus exhaust contamination into the atmosphere from the hood line. Breakage of the high pressure helium line inside the glove box can be sensed and monitored. Automatic shutoff of this line is essential in event it should rupture or carry excessive flow. To achieve this goal, a flow sensing switch was placed in the line and set to activate by an excessive flow. The maximum flow level is surpassed under operating conditions when the large high vacuum valve is open or closed. To override this condition, the helium flow valve will allow excessive gas flow for a period of approximately $30 \mathrm{sec}$ before closing.

It is possible to over pressurize this chamber. To guard against this, a differential pressure switch has been placed on the vacuum chamber to sense the chamber pressure as referenced to the glove box pressure. The vent valve is automatically closed when the differential pressure between the hood and the vacuum chamber reaches a -1 in. of water. This condition causes 
a small influx of the hood atmosphere into the vacuum chamber as it is opened. The ensuing pressure differential is so small that the hood box pressure is only slightly affected as the chamber is opened.

Excess Negative Pressure

It is conceivable, with the vacuum equipment available, that the glove box could be evacuated to the point where gloves could be pulled off inside the box. Three ways of producing excessive negative pressure are by (1) a leak in the vacuum system or a partially closed door as evacuation of chamber is started, (2) opening the vacuum chamber while it is at a very low negative pressure, and (3) malfunction of the E4 Fisher valve. When the vacuum chamber is being evacuated by the mechanical pump, the hood chamber conceivably could be partially evacuated if the vacuum chamber door is not properly closed. A leak in one of the feedthroughs could create the same condition by pulling hood chamber atmosphere into the chamber and exhausting it through the mechanical pump. This condition is controlled by a differential pressure switch designed to sense the pressure of the hood box and is set to cut off the mechanical pump any time the pressure inside the hood box goes below -3 in. of water, or above -0.5 in. of water. Opening of the vacuum chamber at a low negative pressure could conceivably create a very low negative pressure inside the hood box. A differential switch placed in the vacuum chamber indicates the pressure in the chamber when it reaches - 2 in. of water. Preventing the occurrence of such a condition is a matter of operator education. Water pressure of -4 in. may be achieved if the E4 Fisher valve malfunctions and opens. In this event, the mechanical pump would be shut down due to the differential pressure switch interlock. Pressure of this magnitude is not hazardous and no precautions have been established to override it. To pull the glove from the glove box 
and suck it in would require considerably more negative pressure than $-4 \mathrm{in}$. of water. It would require on the order of -1 psia.

\section{VACUUM SYSTEM}

The vacuum system consists of a mechanical pump, diffusion pump, fore line valve, high vacuum valve, backing valve, and vacuum chamber. The hazard of valve operation is in the breaking of the high pressure helium gas line, located inside the glove box. Gas flow through this line is monitored and flow in excess of a certain rate will activate a 30-sec time delay interlock to shut the supply valve. If the high flow rate continues, the mechanical pump interlock with the differential pressure switch activates to sense the pressure of the hood. In the event this pressure drops below - 3 in. of water or goes above -0.5 in. of water, the mechanical pump shuts down automatically. Safety problems are such that, unless the diffusion pump is backed by the mechanical pump, the oil located in the diffusion pump may oxidize and burn very badly, thus requiring a major overhaul of the diffusion pump. The diffusion pump also requires cooling water to condense and prevent the oil vapors from actually pressurizing the diffusion pump section. Three interlocks assure safe operation of the diffusion pump. One interlock prevents operation unless the pump is evacuated below $50 \mu$. This pump is also protected by an over-temperature switch which shuts down the pump if the water cooling fails. The diffusion pump is also interlocked to the mechanical pump and will shut down in the event the mechanical pump is inactivated for any reason.

The vacuum chamber is protected by the differential pressure switch which permits the vent valve to bleed the vacuum chamber up to near glove box pressure. This unit has already been described. The valving unit for the vacuum system is an 
NRC automatic valve controller. This unit, interlocked with the differential pressure switch on the glove box, also controls the mechanical pump interlock. In the event the glove box becomes over or under pressurized, or in event of a power failure, this valve control unit will automatically close all vacuum system valves.

WATER SYSTEM

The radioactive hazard of the material in process dictates use of a closed water system to prevent any contamination of the water drain system. To achieve this, a heat exchanger is used to cool down the water of the recirculating water system. Safe operation demands the system be monitored and equipped with an automatic safety interlock to prevent water from overflowing into the air exhaust system or flooding chambers where water leaks could develop. The water input into the heat exchanger has an endless supply and therefore must be monitored with the capability of a valve shutoff in event of a leak. The recirculation water system has a limited supply. It is conceivable that, in certain boxes, the total recirculating water reservoir could be retained prior to development of a hazardous condition. The unit would then automatically be shut down by the pressure interlock activated by low water pressure.

The heat exchanger is located under glove box No. 2. A sona switch (water detector) is located in the bottom of this box to sense water and shut down the heat exchanger in the event water is sensed in the bottom of this box. This is done because it is impossible to differentiate between a break in the recirculating water line, or a break or leak in the heat exchanger input line. The water level is also sensed in the recirculating water system reservoir. It is conceivable that an internal break in the heat exchanger piping could develop 
and leak water into the closed loop water system, thus providing an endless supply of water to the recirculating water system. In the event that the reservoir of the recirculating system exceeds the set point of the sona switch, it automatically valves off the water to the heat exchanger. No additional sensing mechanisms are necessary in any of the hoods due to the limited capacity of the recirculating system and the retention capacity of the hoods. The system is designed to shut down automatically when all stored water is drained from the unit, and to guard against any hazardous condition at any time preceding completion of the draining process.

\section{SPUTTERING SYSTEM INSTALLATION}

A vacuum system of maximum flexibility was desired so that several evaporation methods could be evaluated in developing a process to deposit over the fueled microspheres. Also desirable for use with the sputtering unit was a compatible vacuum deposition method. With these requirements in mind, sputtering equipment was evaluated. Balzer's Sputron II appeared to provide the necessary flexibility. The Balzer's unit as depicted in Figure 3 is a triode sputtering system. Installation of this particular system upside down to its designed geometry was required, as illustrated in Figure 4. Basically, then, the ionization chamber was mounted onto the base plate with the target assembly mounted at the top of the chamber. The electromagnet used to focus the ion beam onto the target was originally located on the outside of the bell jar system. Due to glove box space limitations, it was impossible to locate the magnet on the outside of the chamber, and it was thus moved inside the chamber as shown in Figure 5. The relocation of the magnet helped the deposition rates and reduced the necessary power input into the magnet to focus the ion beam onto the target. One of the requirements created by locating the magnet inside the vacuum chamber was water cooling to prevent overheating and consequent shorting out of the 
BNWL- 1287

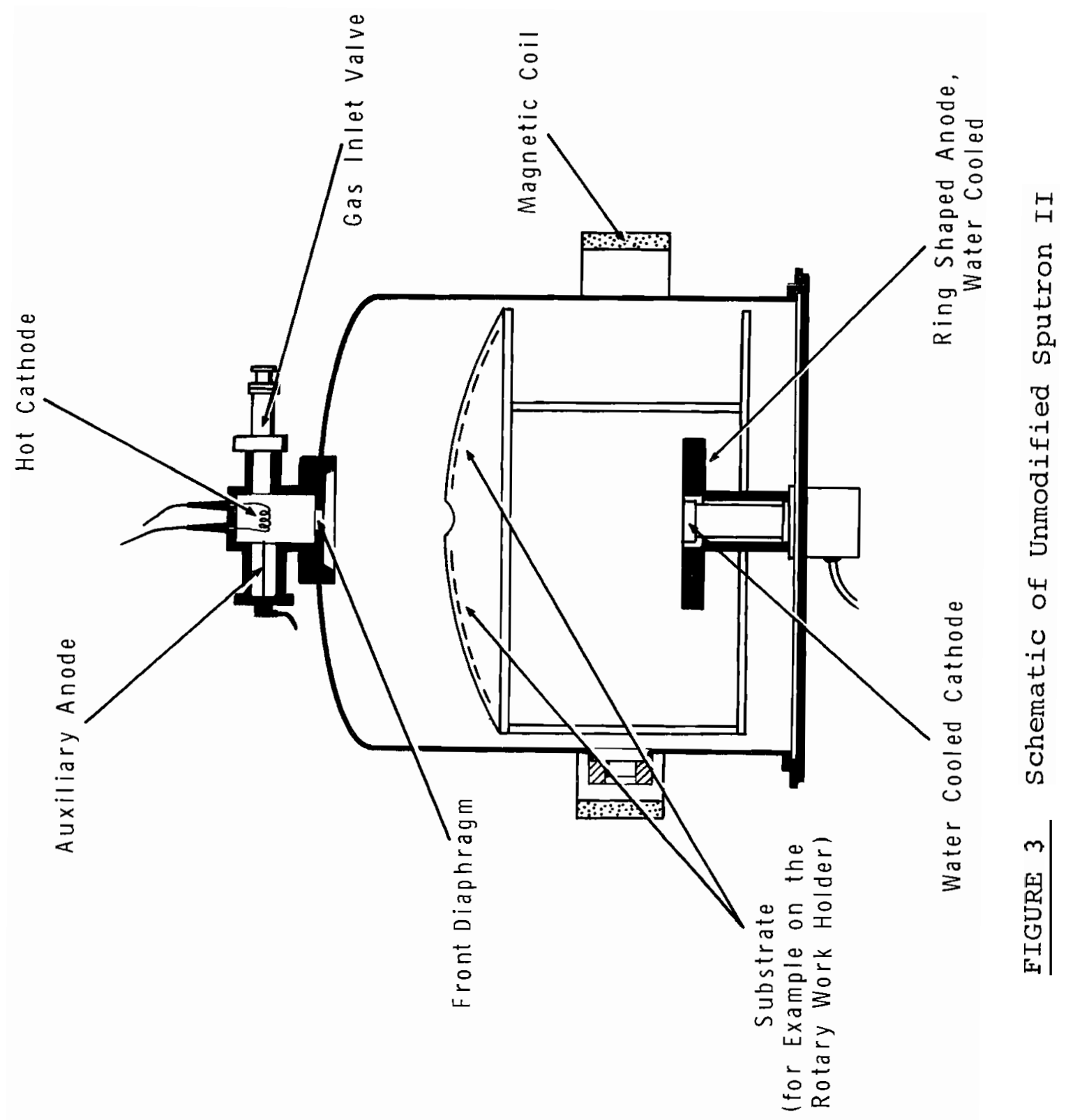


BNWL- 1287

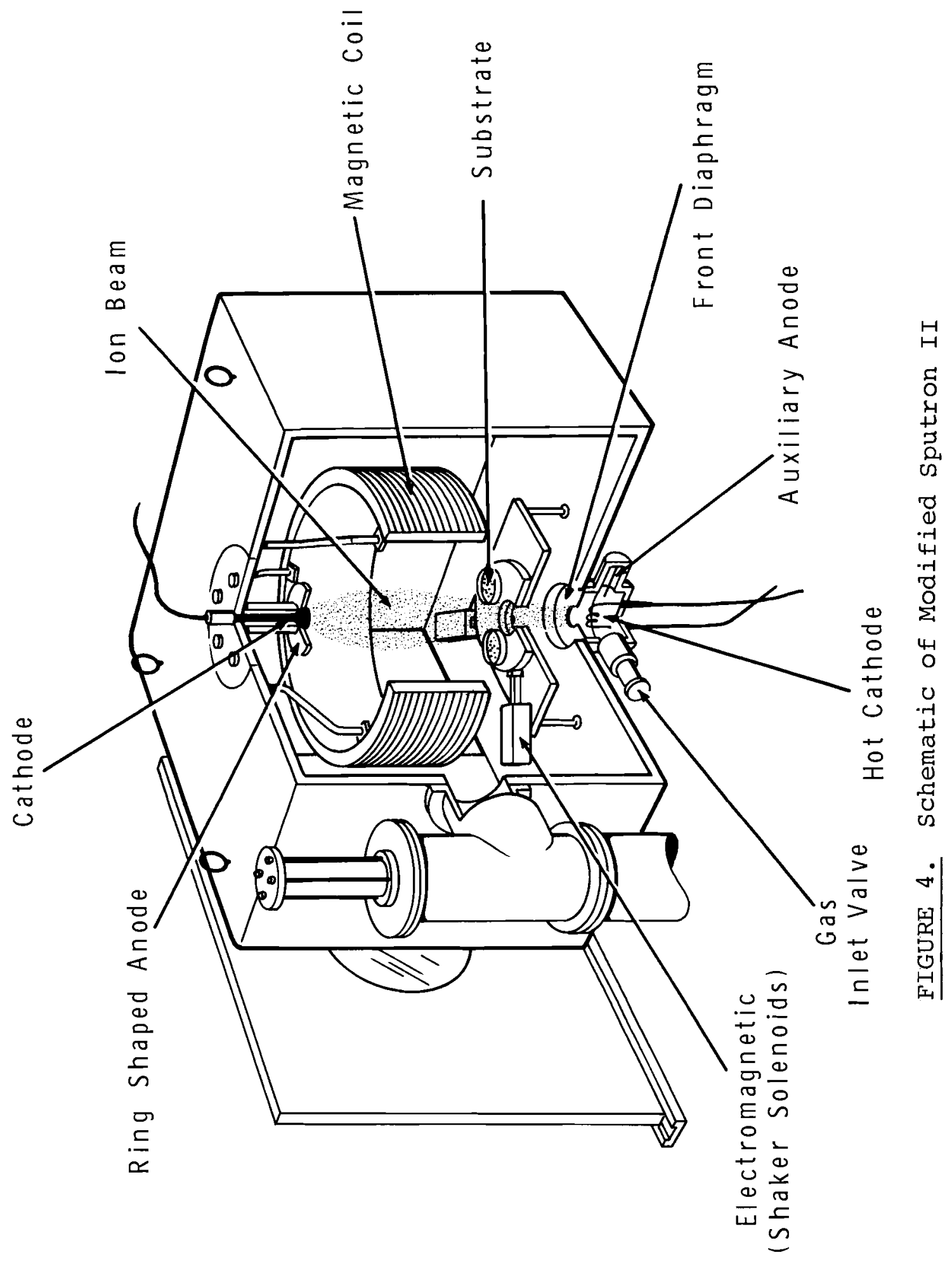




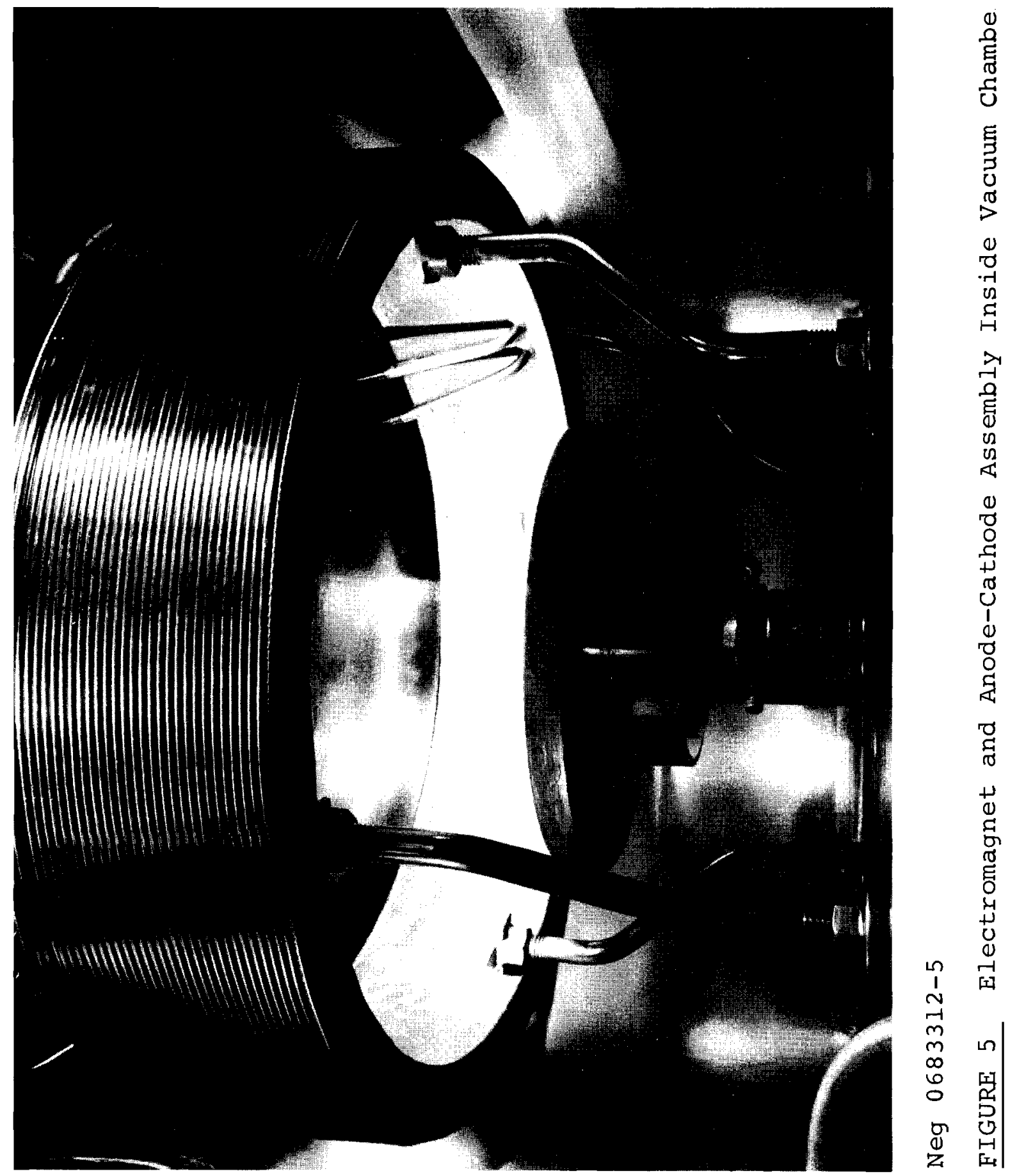


magnet. The substrate areas consisted of microsphere container dishes located in a circular pattern as seen in Figure 6. Note the hole in the center of the substrate holder, which allows the ion beam to pass through for bombardment onto the sputtering target.

Figures 5 and 6 depict the internal installation of the sputtering unit. Figure 7 shows the top of the vacuum chamber with the water cooling attached to the anode and cathode assembly of the sputtering system. The sputtering system is protected by the water interlock, vacuum interlock, and rear door interlock. The water interlock consists of two flow devices for monitoring the water flow into the target and ion chamber cooling housing. In the event insufficient flow is sensed, the unit is automatically shut down and cannot be started until flow has been restored. A vacuum interlock connected to a relay controlled by a thermocouple senses the pressure in the vacuum chamber. The sputtering unit is inoperable until a vacuum of $50 \mu$ or less has been achieved. The vacuum interlock is provided more as an operator safety measure rather than a device for protecting the sputtering unit. The rear door interlock is a safety mechanism for personnel protection and can be overridden in the event the unit must be serviced or inspected while in an operating condition. In addition to this, the sputtering system is interlocked to the overall vacuum system operation through the thermocouple interlock mechanism. A malfunction of the pumping system during disengagement of the mechanical pump will result in automatic shutdown of the sputtering unit through the thermocouple relay interlock. 

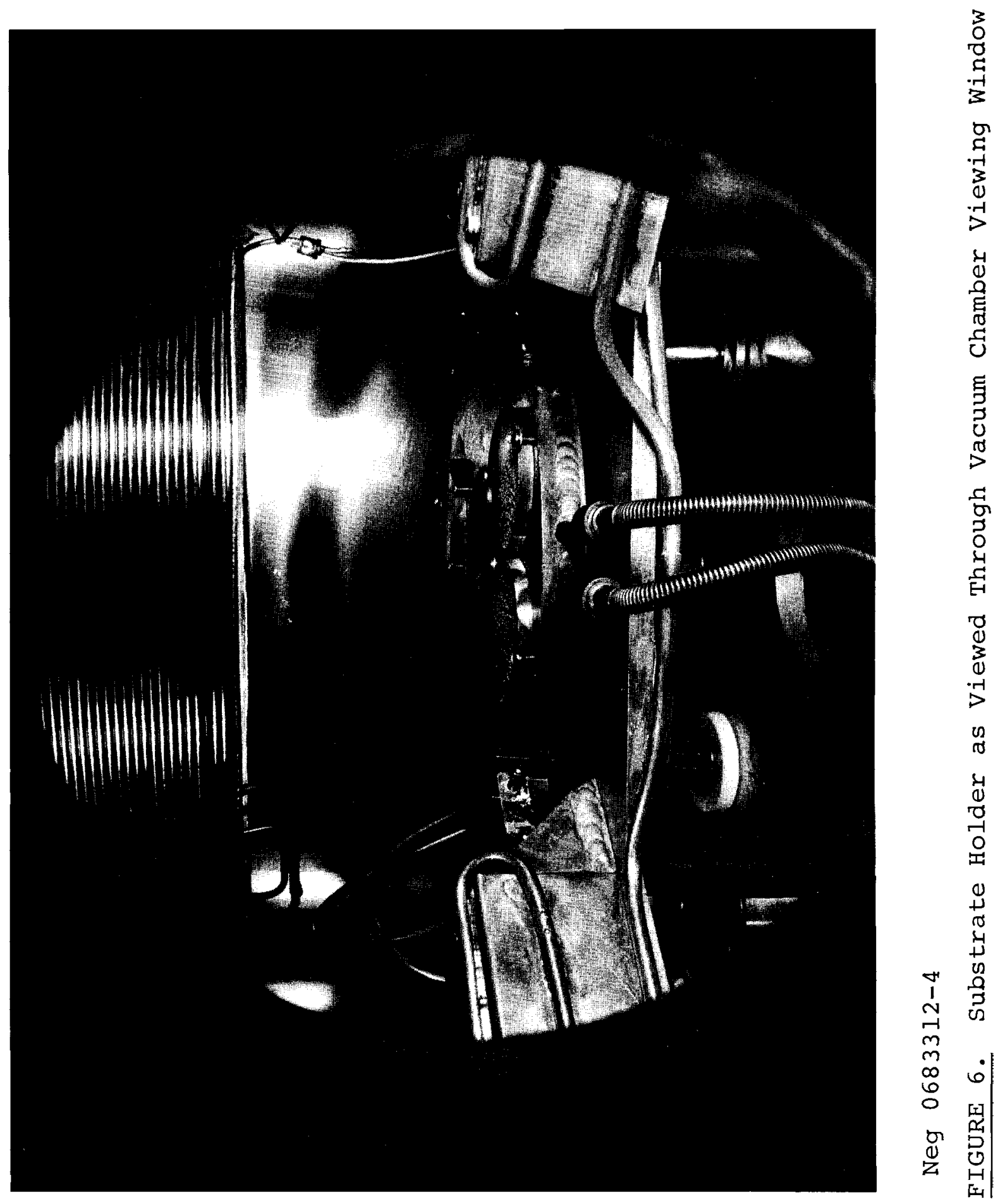
BNWL - 1287

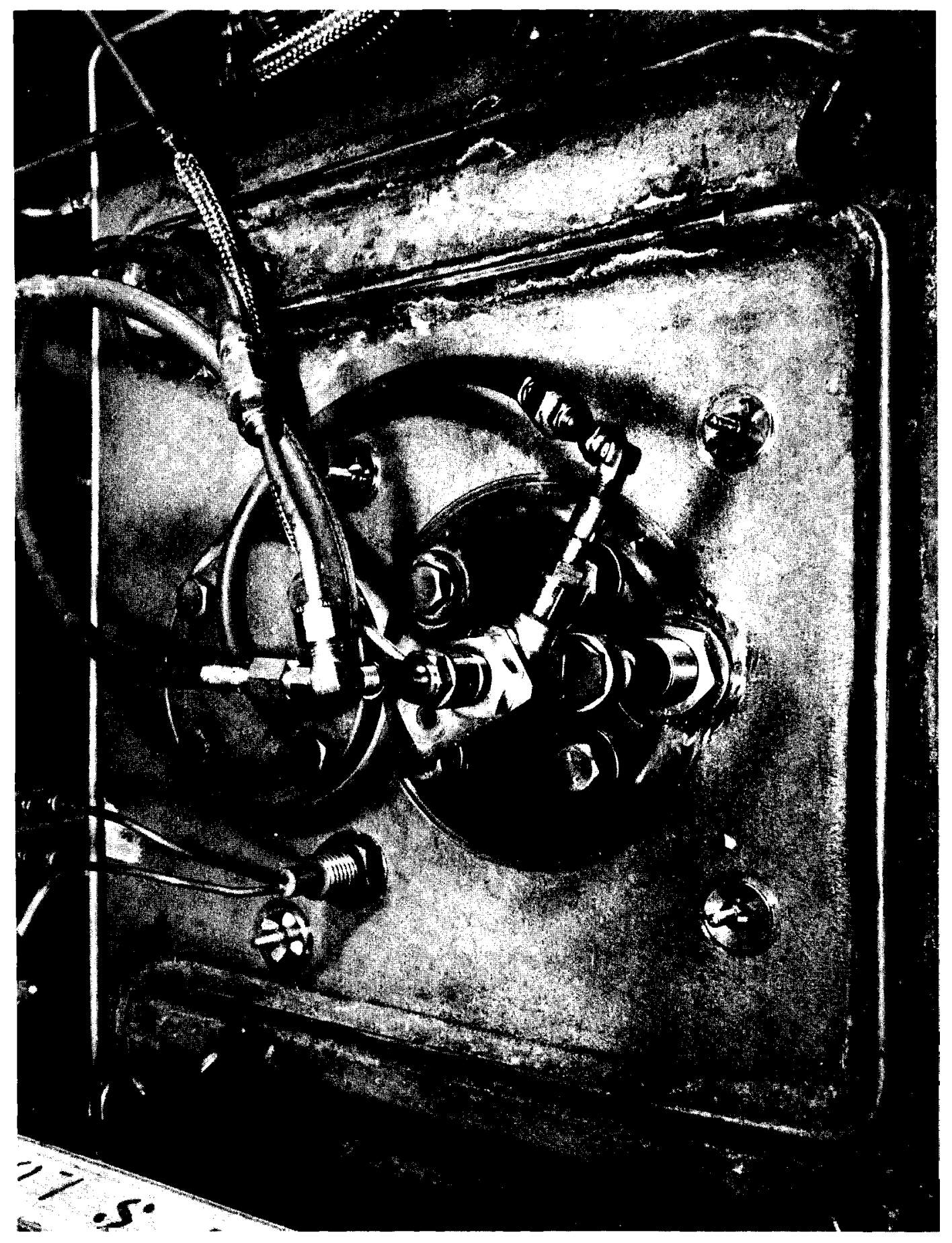

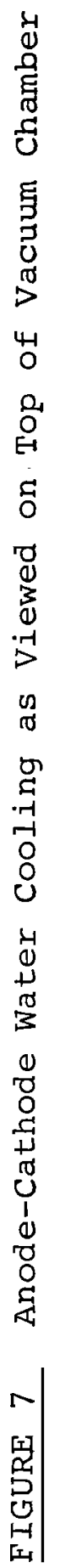




\section{MICROSPHERE SHAKER TABLE}

A special microsphere shaker table designed and fabricated for the sputtering system can be seen in Figure 8 . This view was taken through the viewing port of the sputtering unit. This particular shaker system is an outgrowth of a system previously developed for the vacuum vapor deposition of the rare earth metals onto the hollow microspheres. Sticking of the microspheres under the sputtering operation, due to better adherence of the film, was indicated by our experience. Two electromagnetic vibrators were fabricated and installed to prevent this occurrence. A special power supply allowing operation of either or both of the electro-magnetic vibrating units was fabricated. This unit has three basic controls consisting of phase control, amplitude control, and frequency control. The provision for a special phase circuit allows adjustment of the phase between the two units from 0 to $90^{\circ}$. By adjusting the phase relationship between the two electromagnets, it is possible to get a rotary vibratory motion. The amplitude control simply controls the amount of power into each electro-magnetic vibrator which, in turn, affects the accelerating force with which the unit moves. The frequency control consists of manual frequency control and ramp frequency control. The frequency is controllable from 3 to $30 \mathrm{~Hz}$, and is automatically controlled with the ramp control over a frequency range of $\pm 5 \mathrm{~Hz}$ centered about a selected reference frequency. With these controls, we found that the spheres could be moved in a rotary or back and forth fashion at the choice of the operator. When sticking occurs, the operator can increase the amplitude control to produce a more violent shaking action. Quite often we found that the spheres had been shaken loose allowing the deposit to continue. Figure 9 is the wiring diagram of the shaker table power supply. 
BNWL -1287

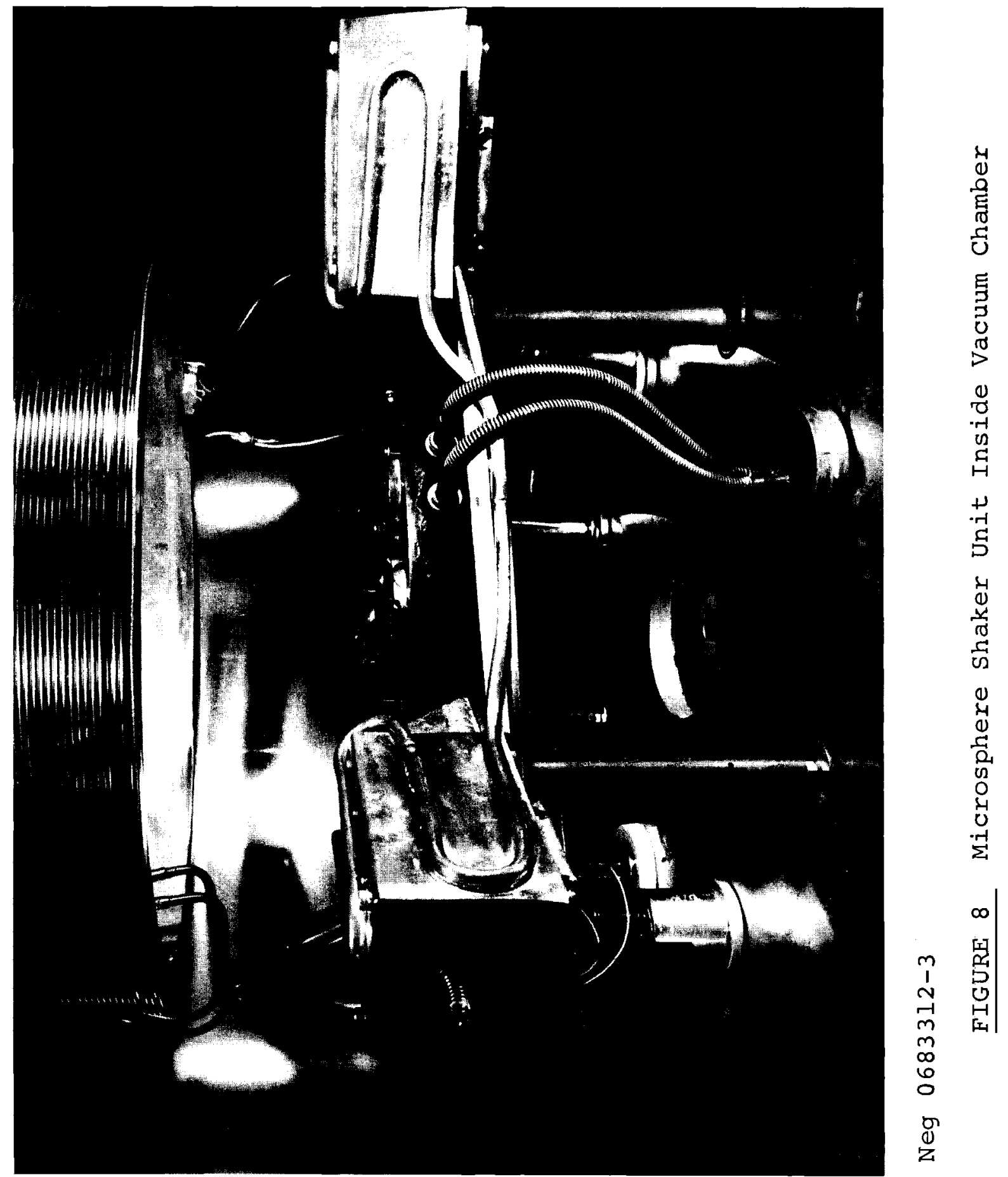




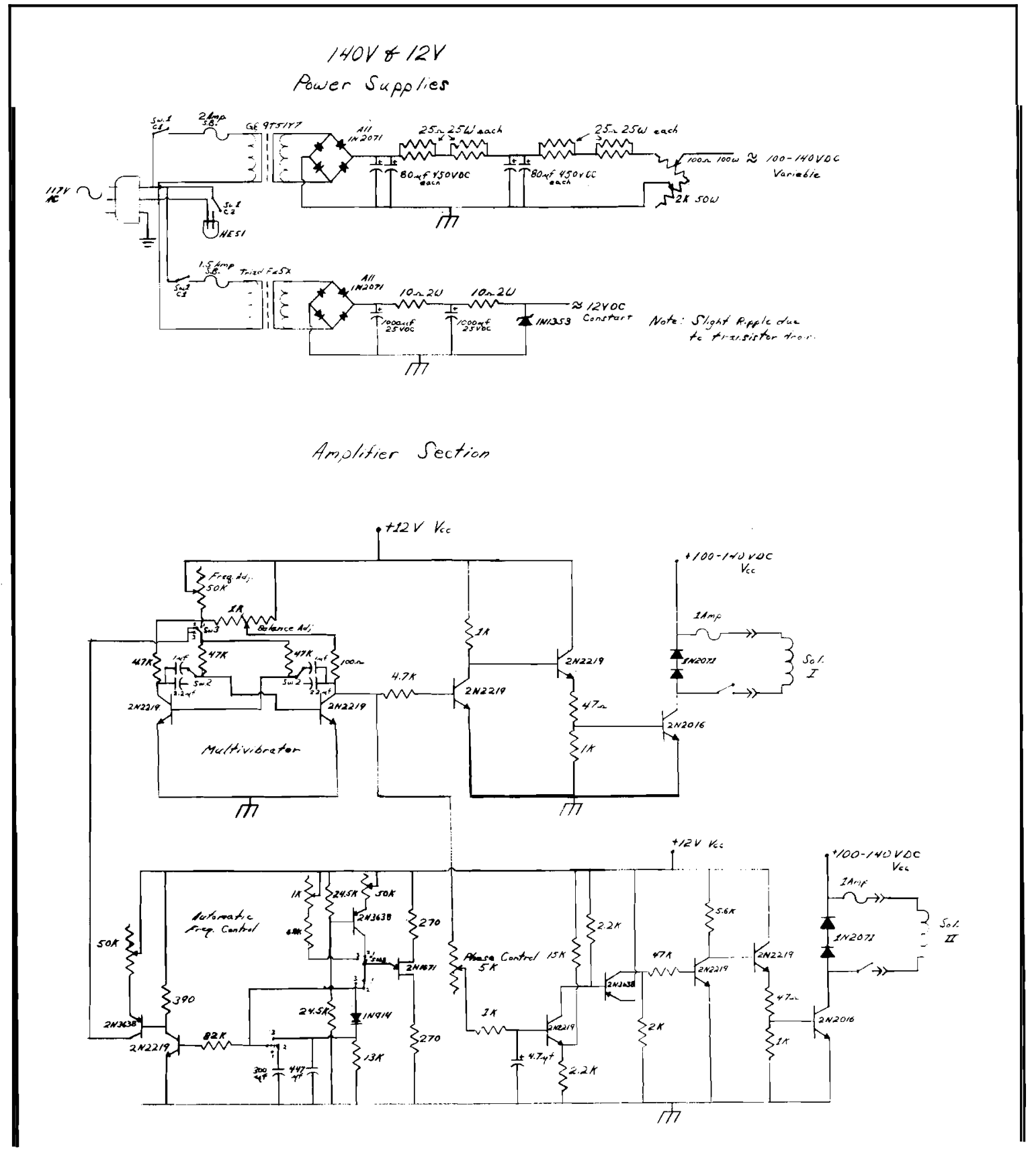

Neg 0693949-1

FIGURE 9. Wiring Diagram of Shaker Unit Power Supply 
BNWL -1287

\section{SPUTTERING SYSTEM OPERATION}

The modified Balzer's Sputron II used in the glove box has has the following operational parameters:

- Arc Voltage - This is the dc voltage between the hot cathode and the anode.

- Arc Amperage - This measures the current passing through the anode.

- Sputtering Amperage - This indicates the current drawn through the target.

- Sputtering Voltage - This measures the voltage between the anode and the target.

Filament Amperage - This measures the current passing through the hot filament.

- Vacuum Chamber Pressure - This is measured by an ion vacuum gage.

The objective of the sputtering deposition, to acquire a highly adherent continuous film in the shortest possible time, can be accomplished by the proper setting of the preceding parameters. The settings of these parameters are influenced by maintaining the lowest possible vacuum which will aid in producing a purer film and in reducing the number of collisions or scattering advents of the depositing material prior to deposition onto the substrate, and acquiring high rates to minimize the time necessary to deposit the desired thickness.

The sputtering unit can be broken down into three basic areas consisting of the ion generating chamber, the target area, and the substrate region (Figure 4). The ionization chamber contains the hot cathode, the auxiliary anode, the gas inlet valve, and the front diaphram used to achieve a pressure drop between the ionization chamber and the vacuum chamber during operation. The front diaphram in the ionization chamber increases the pressure of the ionization chamber by a factor 
of approximately 10 in comparison to the vacuum chamber. This increase serves to maintain a higher vacuum in the substrate region and to provide a chamber where the argon is more efficiently ionized. The auxiliary anode facilitates striking the arc at low pressures. The sputtering parameters are monitored by the amperage and voltage on the sputtering target. These parameters can be controlled only indirectly by the chamber pressure and by the voltage and amperage of the hot cathode. The parameters controlled by the operator are arc current, hot cathode amperage, chamber pressure, and magnetic field for ion plasma focusing. By increasing the arc current, the sputtering amperage is increased or decreased almost directly for constant pressure. The sputtering amperage is also affected and can be maximized by adjusting the magnetic field.

Increasing the pressure increases the number of ions generated for a given arc voltage. The net result is an increase in the ion current. The normal operating parameters are: ion amperage, $1.3 \mathrm{~A} ;$ target voltage, $2 \mathrm{kV}$; filament amperage, $80 \mathrm{~A}$; arc amperage, $40 \mathrm{~A}$; arc voltage, $35 \mathrm{~V}$; and pressure, $9 \times 10^{-4}$ Torr. With these parameters, rates depending on material vary from 100 to $300 \AA / \mathrm{min} .1$

Figure 10 is the metalograph photo of a sputtering run onto fueled polonide microspheres. The fuel is sandwiched between the microsphere and the sputtered film. The deposition time was about $10 \mathrm{hr}$. Considering the many heat treatments and the other various handling procedures, the film looked acceptable in that the polonide fuel was protected by the sputtered film. 


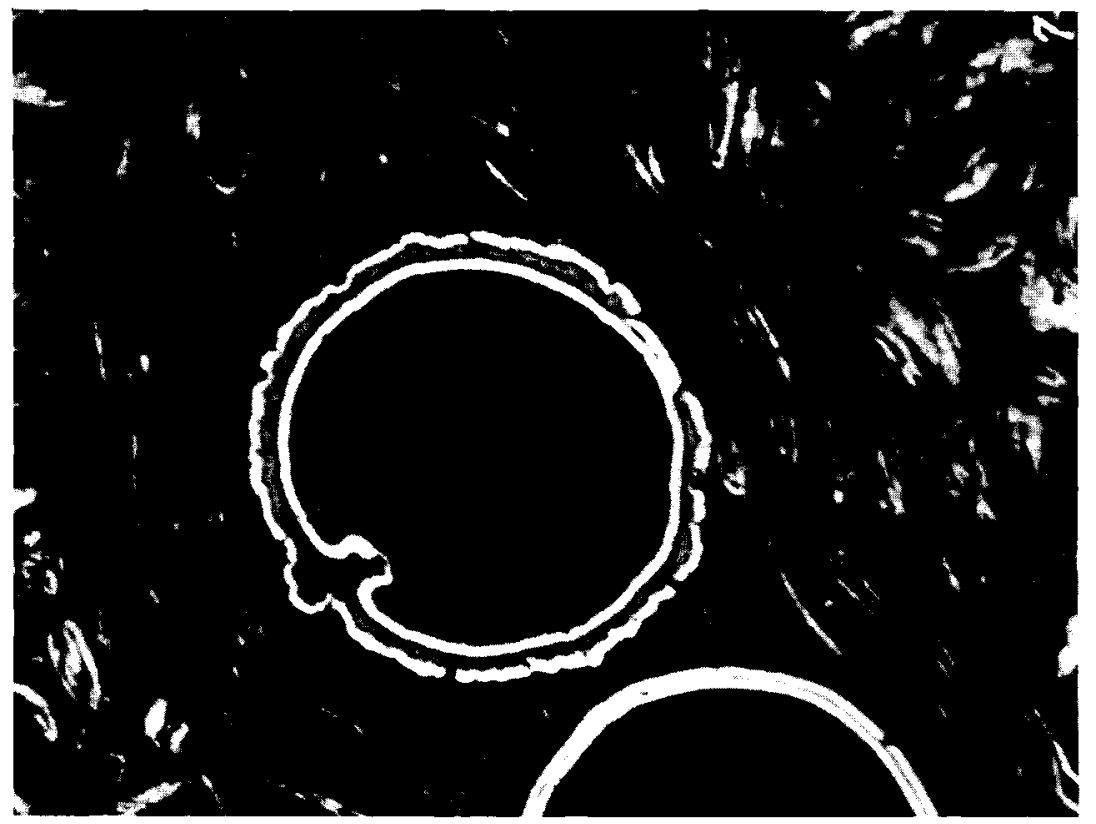

FIGURE 10. Metallography of Fueled Microsphere with Sputtered Protective Film Overlay

\section{CONCLUSIONS}

The interlock system has been in operation for over 6 months. During this period, it has shut down the system several times because of abnormal glove box pressure and inadequate water flows. It is possible, by abruptly pumping the gloves, to upset the glove box pressure and thus cause the system to shut down. The vacuum chamber differential pressure switch has prevented any problems from over or under pressurization, while the interlock system has enabled a complex system to operate safely. 


\section{DISTRIBUTION}

No. of

Copies

OFFSITE

1

AEC Chicago Patent Group

G. H. Lee

1

AEC Division of Isotopes Development

J . N. Maddox

2

AEC Division of Space Nuclear Systems

J. S. Griffo

J. A. Powers

200 AEC Division of Technical Information Extension

$1 \quad$ Mound Laboratory

C. J. Kershner

\section{ONSITE-HANFORD}

1

2

2

3

65
AEC Chicago Patent Group

R. K. Sharp (Richland)

AEC RDT Site Representative

P. G. Holsted

AEC Richland Operations Office

C. L. Robinson

B. A. Ryan

Battelle Memorial Institute

Battelle-Northwest

A. L. Bement

G. E. Adamson

C. A. Bennett

D. W. Brite (6)

T. D. Chikalla

W. J . Coleman (10)

D. R. de Halas

J . L. Deichman

J. E. Hanson

R. L. Gordon 
Battelle-Nortwest (contd)

B. P. Hildebrand

J. H. Jarret t (20)

R. S. Kemper

R. L. Knecht

C. E. Leach

D. C. Lehfeldt

J. V. McMaster

R. L. Moore

R. E. Nightingale

B. A. Ryan

T. C. Schneider

W. F. Sheely

K. R. Sump

H. H. Van Tuyl

D. C. Worlton

Technical Information (5)

Technical Publications 